\title{
SERUM PRECIPITABLE IODINE CONCENTRATIONS DURING PREGNANCY ${ }^{1}$ \\ By MARTIN HEINEMANN, CARL E. JOHNSON, AND EVELYN B. MAN \\ (From the Departments of Medicine and Obstetrics, and the Biochemistry Laboratory, Department of Psychiatry, Yale University School of Medicine, New Haven)
}

(Received for publication June 10, 1947)

Circulating thyroid hormone is measured more accurately by determination of serum precipitable iodine than of basal metabolic rate ( 1 to 8 ). Since the latter increases during pregnancy (9 to 14) serum precipitable iodines were investigated in 43 pregnant women and followed in some subjects after delivery.

\footnotetext{
${ }^{1} \mathrm{~A}$ preliminary report of this investigation was included in the Proceedings of the Thirty-Eighth Annual Meeting of the American Society for Clinical Investigation, J. of Clin. Invest., 1946, 25, 926.
}

\section{SUBJECTS AND METHODS}

The ages of the 43 subjects ranged from 21 to 44 years. Twenty-nine subjects were normal; they had neither family nor personal histories suggestive of metabolic disturbances. Physical examinations did not reveal abnormalities in pulse rate, pulse pressure, size and consistency of the thyroid gland, tremor or eye signs. Fifteen drops daily of Lugol's solution were given to 2 of the subjects for 5 and 9 weeks, respectively. One subject received 100,000 units of estradiol in oil intramuscularly within 1 week. Of the remaining 14 women, 4 had hyperthyroidism, 4 miscarried, and 6 who did not miscarry were given

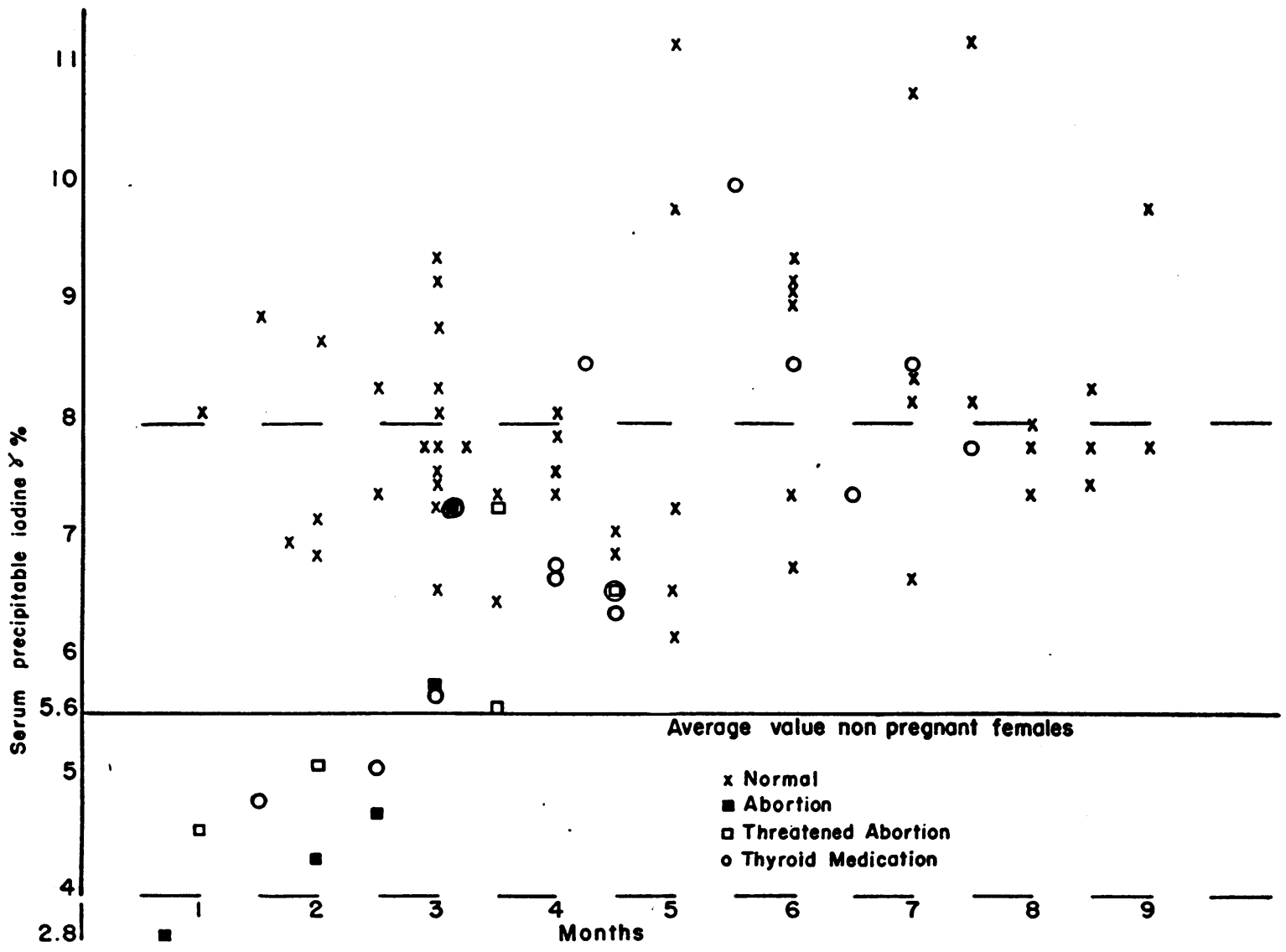

Fig. 1. Serum Precipitable Iodines of 39 Pregnant Women, Exclusive of Patients WITH HYPERTHYROIDISM

Broken horizontal lines represent the upper and lower limits of normal range of serum precipitable iodine (4.0 to 8.0 gamma per cent). Solid horizontal line is 5.6 gamma per cent, the average normal value from statistical analysis (16). 
desiccated thyroid although the diagnosis of hypothyroidism could be made in only 1 .

The proteins of the serum were precipitated with zinc sulfate and sodium hydroxide as described previously (5) and the iodine included with the precipitated proteins was measured by the Riggs and Man permanganate acid ashing method (15).

With this method the range of concentrations in normal humans is 4.0 to 8.0 gamma per cent with a mean value of $5.6 \pm 1.3$ gamma per cent. No statistical difference was found between normal males and normal non-pregnant females (16). Determinations have been made in duplicate, but owing to the difficulties of the visual titration end-point a maximum difference of 1.0 gamma per cent may occur between the 2 samples. For this reason differences of 1.0 gamma per cent between the averages of 2 successive determinations of serum precipitable iodine on the same patient do not indicate a significant change.

\section{RESULTS}

In Figure 1 the concentrations of serum precipitable iodines of 29 normal pregnant women ranged between 6.2 and 11.2 gamma per cent. The majority of the iodine concentrations were high normal or were above the upper limit of the normal range of non-pregnant women (8.0 gamma per cent). Elevated values were noted as early as 3 and 6 weeks after conception. The concentrations of serum precipitable iodines did not increase during the subsequent course of pregnancy (Figures 1 and 2). In 2 instances maternal venous and umbilical blood serum had identical amounts of serum precipitable iodine. The elevation of serum precipitable iodine during pregnancy soon subsided after delivery (Figure 2). The drop occurred in some instances as early as 1 week postpartum. In 3 patients whose serum iodine was measured 2 to 4 months after delivery there was a further decrease.

In 10 instances women who threatened to abort or aborted had serum precipitable iodines low for normal pregnancy. In 6 of these patients the iodine concentrations were low in the normal range, 4.3 to 5.8 gamma per cent. One patient on 3 grains of desiccated thyroid miscarried when the serum precipitable iodine was 7.3 gamma per cent and aborted a second time when she was not

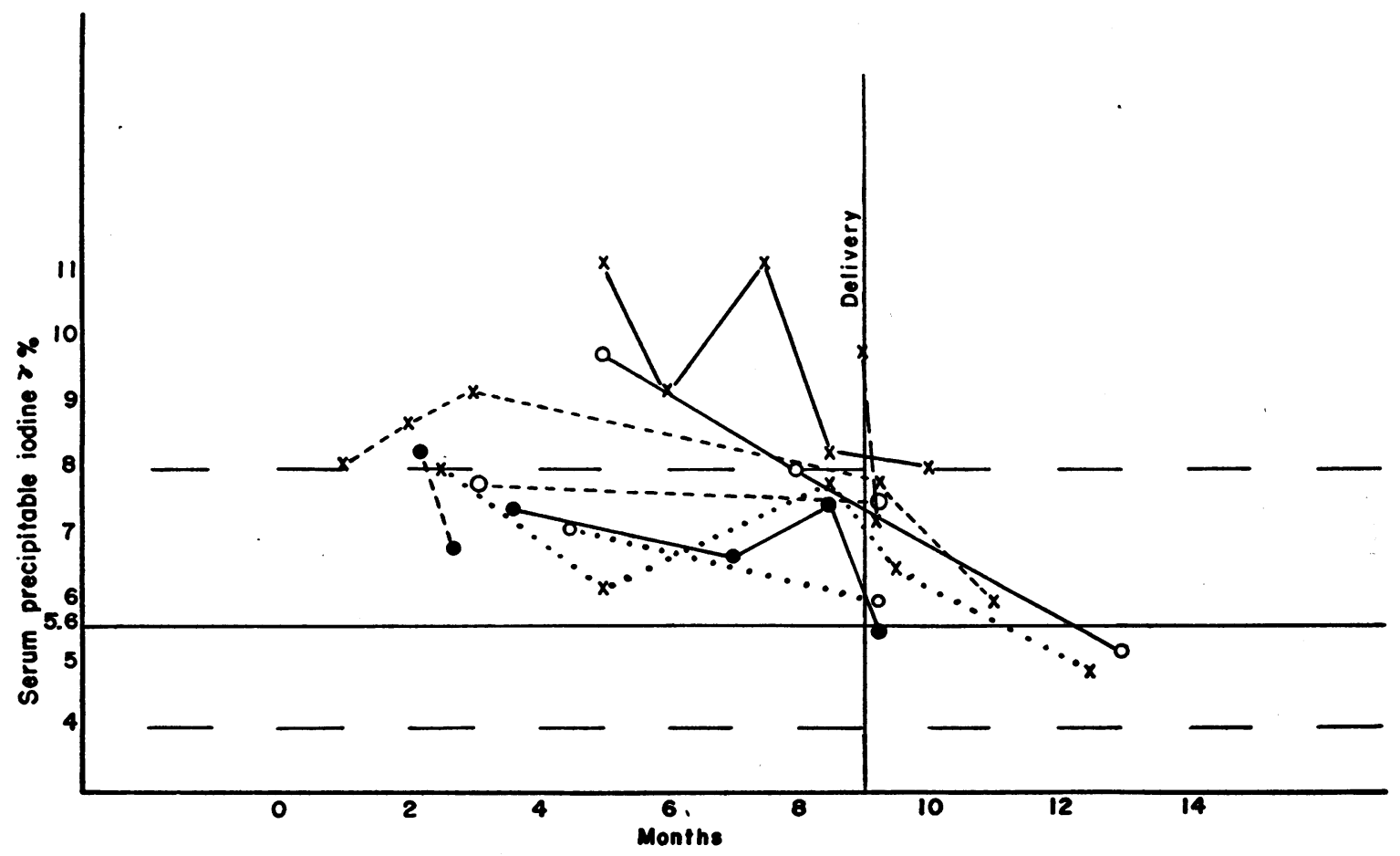

Fig. 2. Serum Precipitable Iodines of 9 Women during and after Pregnancy

Broken horizontal lines represent the upper and lower limits of normal range of serum precipitable iodine (4.0 to 8.0 gamma per cent). Solid horizontal line is $\mathbf{5 . 6}$ gamma per cent, the average normal value from statistical analysis.

Short broken line at $2 \frac{1}{2}$ months connects concentrations before and 13 days after operative termination of cervical ectopic pregnancy. 


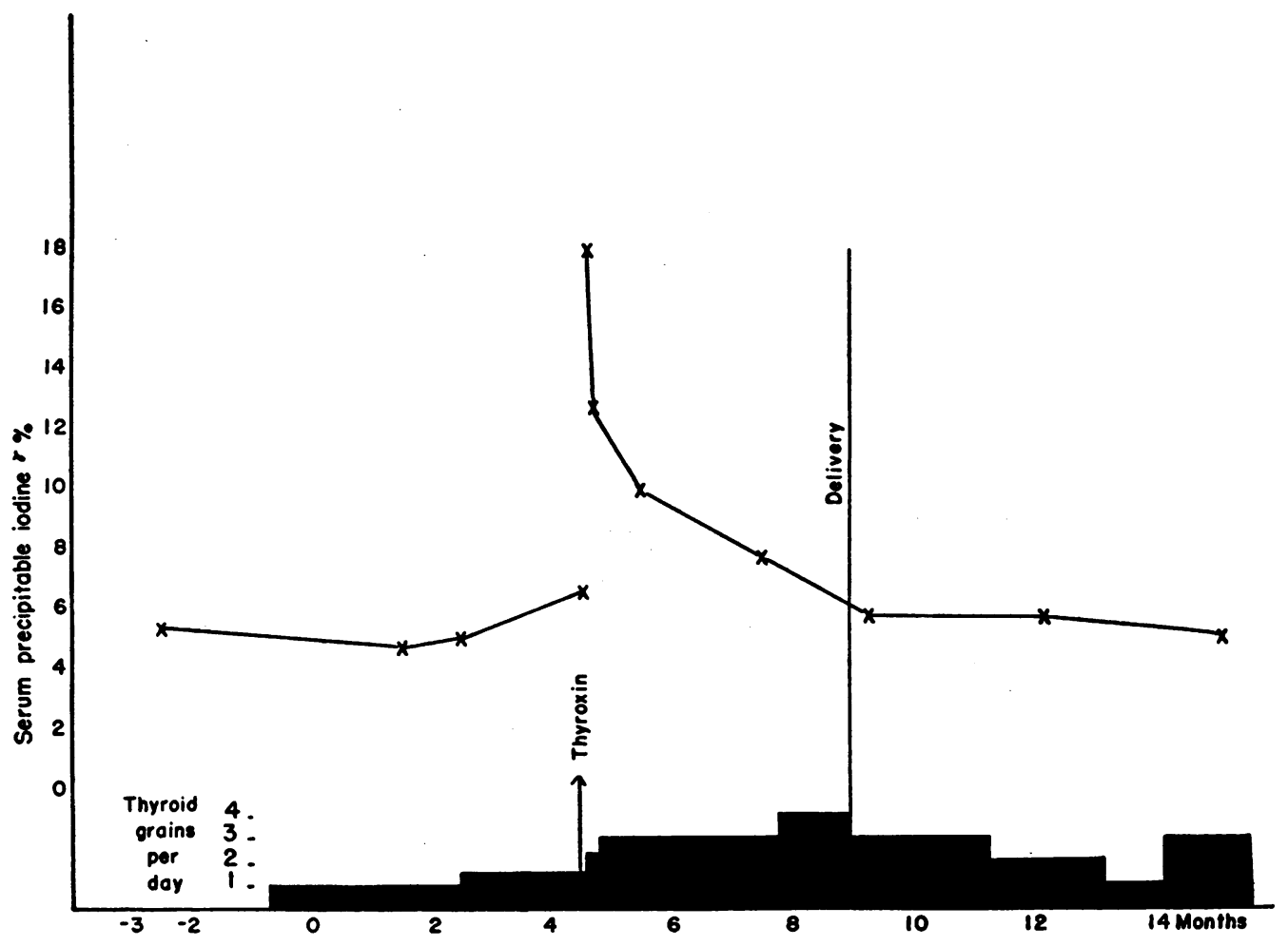

Fig. 3. Serum Precipitable Iodines and Thyroid Medication of a Hypothyroid Patient during aNd after Pregnancy

During the fourth month of pregnancy this patient developed labor pains and profuse vaginal bleeding. Shortly after hospitalization blood was taken for measurement of serum iodine. She was then given $2 \mathrm{mgm}$. of thyroxin intravenously. This was repeated the following day. The markedly elevated serum precipitable iodines occurred 1 and 6 days after the second intravenous injection of thyroxin.

taking thyroid and her iodine was as low as 2.8 gamma per cent. One patient (Figure 3 ) on $1 \frac{1}{2}$ grains of desiccated thyroid daily threatened to abort when her iodine was 6.6 gamma per cent; another patient not on thyroid threatened to, but did not abort when her iodine was 7.3 gamma per cent. When such patients were given desiccated thyroid during pregnancy the serum iodine concentrations increased; but in some instances remained in the lower range of values of normal pregnancy (Figure 1).

The course of the serum precipitable iodine of a hypothyroid woman during pregnancy is shown in Figure 3. In the third month of pregnancy she took $1 \frac{1}{2}$ grains of desiccated thyroid daily. In the fourth month she developed labor pains and began to hemorrhage so severely that in the opinion of the obstetrician an abortion was inevitable. The serum precipitable iodine of blood taken immediately after hospitalization was 6.6 gamma per cent. She was given $2 \mathrm{mgm}$. of thyroxin intravenously on 2 successive days. Desiccated thyroid was increased to 3 and then 4 grains daily during the subsequent course of pregnancy; after the effect of intravenous thyroxin had subsided the serum precipitable iodines were 10.0 and 7.8 gamma per cent. She was delivered of a normal baby at term.

In 3 pregnant women with hyperthyroidism (Figure 4) higher concentrations of serum precipitable iodine occurred than in normal pregnant subjects. These subjects were treated with thiourea and Lugol's solution. All delivered apparently normal babies at term. One patient with hyperthyroidism (not shown in Figure 4) was treated with Lugol's solution alone. 


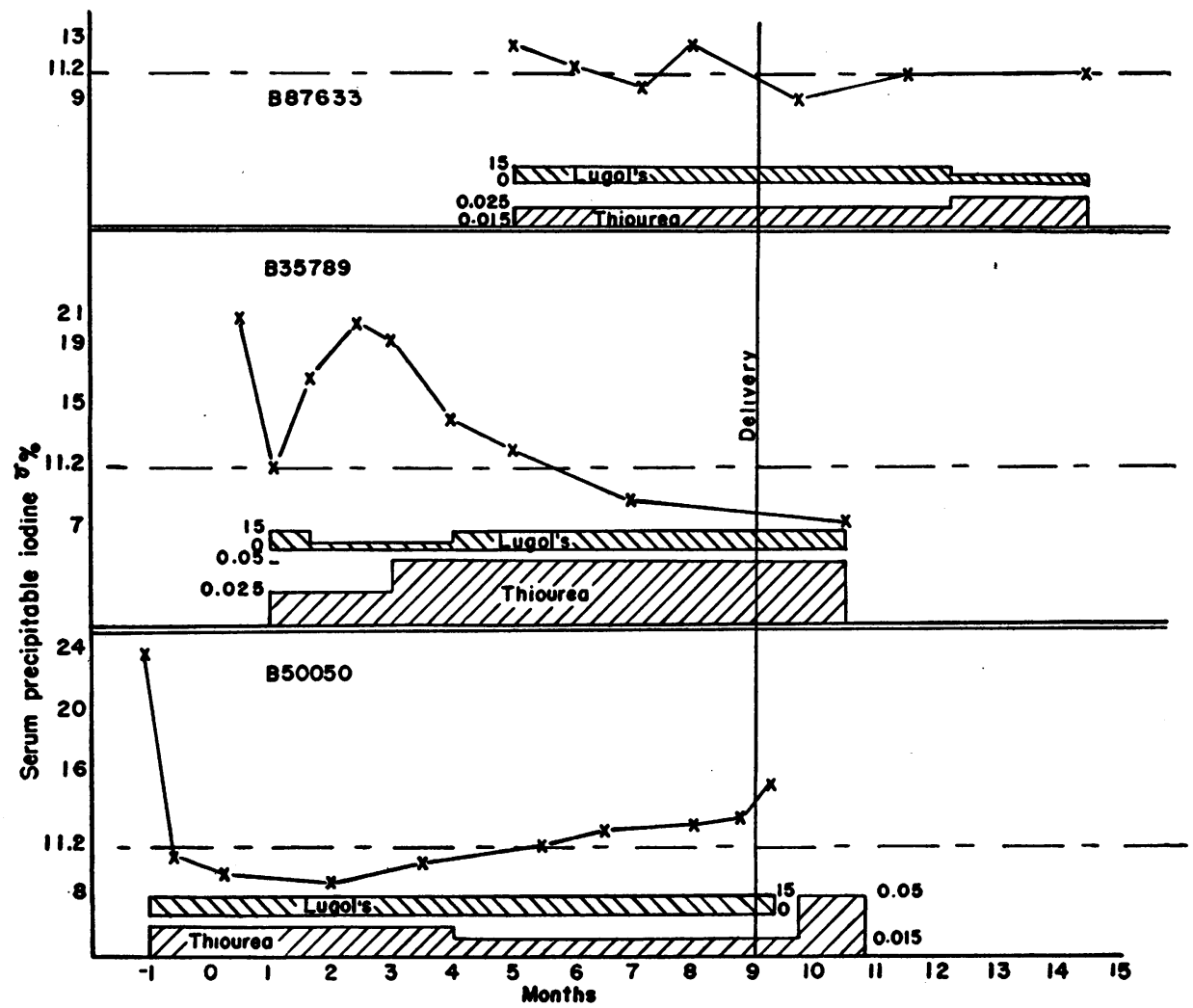

Fig. 4. Serum Precipitable Iodines of 3 Hyperthyroid Patients before, during, and after Pregnancy on Thiourea and Lugol's Solution

Daily doses of thiourea are expressed in grams, Lugol's solution in drops. The broken horizontal lines represent the maximum value, 11.2 gamma per cent, of serum precipitable iodine observed in non-hyperthyroid pregnant women.

B50050 had a diffusely enlarged goiter with thrill and bruit, but no eye signs. After 12 days on 0.025 gram of thiourea and 15 drops of Lugol's solution daily her basal metabolic rate dropped from +68 to +15 per cent, her pulse decreased from 124 to 90 and her serum precipitable iodine fell from 24.2 to $\mathbf{1 0 . 2}$ gamma per cent. Three months after the beginning of medication it was recognized that she was pregnant. Two months later the thiourea dosage was decreased to 0.015 gram daily, but Lugol's solution was maintained at 15 drops daily. Her maximum serum precipitable iodine remained between 11.5 and 13.1 gamma per cent during pregnancy.

Hyperthyroidism with diffuse enlargement of the thyroid, fine tremor of tongue and fingers, but without eye signs, was recognized in B35789 when she was 2 weeks pregnant. After 2 weeks' medication with 0.025 gram of thiourea and 15 drops of Lugol's solution daily, clinical improvement was associated with a decrease in basal metabolic rate from +56 to +23 per cent, in pulse rate from 82 to 68 , and in serum precipitable iodine from 21.1 to 11.2 gamma per cent. Subsequently the symptoms of hyperthyroidism increased and the serum precipitable iodine rose to 20.7 gamma per cent. Thiourea dosage was doubled to 0.05 gram per day. The patient was maintained on this dosage throughout pregnancy.

B87633 did not develop symptoms of hyperthyroidism until the fifth month of pregnancy. This patient had only mild symptoms of hyperthyroidism, the basal metabolic rate was +25 per cent. On a small amount of thiourea, 0.015 gram daily, and 15 drops of Lugol's solution her hyperthyroidism was controlled throughout pregnancy. Thiourea was increased and Lugol's solution was decreased $3 \frac{1}{2}$ months after delivery. 


\section{DISCUSSION}

The elevation of serum precipitable iodine of pregnant women is not associated with clinical signs of hyperthyroidism or with demonstrable increases in oxidative processes. As mentioned before there were neither tachycardia, increased pulse pressure, eye signs, nor conspicuous changes in size or consistency of the thyroid gland. Previous reports from this laboratory $(1,5)$ have stressed that serum precipitable iodines above $\mathbf{8 . 0}$ gamma per cent indicate overactivity of the thyroid gland. In hyperthyroidism administration of Lugol's solution usually effects a drop in serum precipitable iodine $(1,5)$. In 2 women, one 2 months and one 6 months pregnant, 15 drops of Lugol's solution per day for 5 and 9 weeks, respectively, failed to cause any significant variation of serum precipitable iodine. Basal metabolic rates, one measure of oxidative processes, are not elevated before the latter part of pregnancy (11 to 14). The increase in serum precipitable iodine, however, was observed as early as 3 to 6 weeks after conception (Figure 1), and obviously is not correlated with the rise of basal metabolic rate. The increase of iodine during pregnancy is emphasized by the marked diminution following delivery (Figure 2). The elevation of serum precipitable iodine occurs whether the pregnancy be uterine or ectopic. The serum precipitable iodine of a woman with a $2 \frac{1}{2}$ month ectopic cervical pregnancy was 8.3 gamma per cent before, and 6.8 gamma per cent 13 days after operative termination of the pregnancy.

The thought of hyperthyroidism as a feature of normal pregnancy seems untenable. The elevations of serum precipitable iodine more likely constitute an increase in active circulating thyroid hormone which, however, does not affect tissue metabolism in the conventional manner. The normal gestatory changes in hormonal pattern might increase the pregnant organism's need for thyroid hormone and alter its response to it in such a manner that increased thyroid hormone concentrations do not cause a corresponding increase in cellular stimulation.

The patients in Figure 4 are examples of hyperthyroidism with a mild course during pregnancy. These 3 patients developed clinical symptoms of hyperthyroidism at different stages of pregnancy. In comparison with the quantities of thiourea ( 0.04 and 0.28 grams daily) previously reported to control hyperthyroidism in nonpregnant subjects $(17,18)$, these women required small quantities of thiourea. A fourth patient with mild hyperthyroidism was controlled on Lugol's solution alone. Treatment of hyperthyroidism in pregnancy should not depress the serum precipitable iodines much below $8.0^{\circ}$ gamma per cent. Miscarriages have been observed in some patients when serum iodine concentrations were low.

Another possible explanation for the increase in serum percipitable iodine during pregnancy would be that the technique of measuring precipitable iodine in serum from pregnant persons determines compounds chemically different from those in non-pregnant persons. This possibility cannot be excluded at this moment because analyses of the chemical nature of the compounds determined as serum precipitable iodine are not available. For instance organic iodine-containing substances like Priodax, Lipiodol and Diodrast are precipitated with proteins and cannot yet be distinguished from the endogenous iodine compounds of thyroid hormone. At present it would seem that the determinations reported here as serum precipitable iodine do not include fictitious iodine compounds. The increased values of serum precipitable iodine during normal pregnancy seem physiologic and may be as indispensable for the maintenance of pregnancy as changes in pituitary function and hormone concentration. Failure of hormonal adjustment typical of pregnancy will cause premature terminations (19). The intramuscular administration of 100,000 units of estradiol in oil within 1 week to 1 pregnant woman increased the serum precipitable iodine by 1.2 gamma per cent only. Another patient who threatened to abort in the third month of pregnancy was given $70 \mathrm{mgm}$. of stilbestrol intramuscularly. Two days later the serum precipitable iodine was 1.2 gamma per cent above the concentration ( 7.3 gamma per cent) before stilbestrol. In view of the magnitude of the experimental error these increases are equivocal. In some preliminary observations on normal women the serum precipitable iodine decreases from pre- to post-menstrual dates. The differences, however, are too small to prove serum iodine changes during menstrual cycles. Investigation of 
such problems requires a more refined technique than is now available. David and Zener recently reported on "Influence of Iodine Therapy on Blood Iodine and Basal Metabolic Rate in Pregnancy" (20). Their data cannot be compared with ours because the range of normal values in their determinations is at variance with those of Talbot (8), Curtis (21), Taurog (22), and ours (16).

In women with serum precipitable iodine concentrations low for pregnancy it seemed logical to give desiccated thyroid by mouth or thyroxin intravenously. In some instances such therapy seemed to prevent abortions judged inevitable according to obstetrical criteria. It is not implied, however, that thyroid therapy is the treatment of choice for threatened abortion. The small number of observations in this series obviates statistical significance. While more data need to be collected trials with thyroid therapy are indicated if abnormally low serum precipitable iodine concentrations are established and other causes for abortion can be excluded. The effect of thyroid medication did not correspond to the one seen in the non-pregnant entity of hypothyroidism. The pregnant women were given doses of desiccated thyroid as large as 4 to $\mathbf{5}$ grains per day without any evidence of reduced tolerance for desiccated thyroid which is so typical for the hypothyroid patient (23). Such tolerance is similar to that of euthyroid persons (24). This suggests that certain tissues in the pregnant person require thyroid hormone in amounts larger than normal for some as yet unknown function, but unassociated with the overall calorigenic effect. For example, 3 patients (55164, B12368, and B29810), not on thyroid and without clinical signs of hypothyroidism, conceived normally, but threatened to abort between $2 \frac{1}{2}$ and 4 months after conception when their iodines were between 5.1 and 7.3 gamma per cent. Intravenous thyroxin or desiccated thyroid, 1 to 4 grains daily, was administered. They carried through pregnancy to delivery at term. Another example of thyroid medication during pregnancy concerns the 1 definite hypothyroid patient in the series. She was given more desiccated thyroid during pregnancy than either before conception or after delivery (Figure 3). During her first pregnancy in 1942 she took desiccated thyroid. Soon after delivery it was discontinued and the patient observed changes indicating hy- pothyroidism. Without thyroid she subsequently became pregnant three times, but miscarried each time. During the pregnancy shown in Figure 3, although she was on $1 \frac{1}{2}$ grains of desiccated thyroid daily she had vaginal bleeding and labor pains at $4 \frac{1}{2}$ months. After intravenous thyroxin the bleeding and pain stopped. On 3 and then 4 grains of thyroid daily she carried through pregnancy and delivered a normal baby at term. After delivery 3 grains of thyroid daily seemed sufficient, clinically, to control her hypothyroidism.

That patients conceive readily without thyroid medication is suggested by the histories of the 4 previous patients. Observations on them support the theory that thyroid therapy for infertility should be restricted to instances of hypothyroidism. This is equally true for such therapy in menstrual disorders. Data on 1 patient need confirmation. These data may represent the behavior of the serum precipitable iodine in these patients who conceive readily, threaten to abort and then, after thyroid administration, carry through pregnancy. This patient was one who not only failed to develop the increase that usually occurs with pregnancy, but showed a fall in serum iodine. Before conception the serum precipitable iodine was 4.1 gamma per cent. She became pregnant and miscarried in the third week, at which time her serum precipitable iodine was only 2.8 gamma per cent. Three weeks later, still without thyroid medication, the serum precipitable iodine had risen to 4.4 gamma per cent. In this instance pre- and postpregnant iodine concentrations were normal. Thyroid medication did not seem to be indicated either clinically or biochemically.

\section{CONCLUSIONS}

Serum precipitable iodines of 43 pregnant women have been measured during pregnancy and in 11 instances after delivery.

In 29 normal pregnancies, serum precipitable iodines ranged between 6.2 and 11.2 gamma per cent, the normal non-pregnant range being 4.0 to 8.0 gamma per cent. This elevation of serum precipitable iodine was noted as early as 3 weeks after conception, did not increase as pregnancy advanced and decreased rapidly to the normal range after delivery. Elevated serum precipitable iodines are physiologic for normal pregnancies; they do not indicate hyperthyroidism. 
In some patients who threatened to abort, or actually aborted, the serum precipitable iodines were between 2.8 and 5.8 gamma per cent. In such instances the administration of desiccated thyroid should be considered. Thyroid medication for infertility appears to be indicated only in hypothyroid patients.

Hyperthyroidism of 4 pregnant women was controlled easily and pregnancy maintained with Lugol's solution alone, or in conjunction with small amounts of thiourea.

\section{BIBLIOGRAPHY}

1. Winkler, A. W., Riggs, D. S., Thompson, K. W., and Man, E. B., Serum iodine in hyperthyroidism with particular reference to the effects of subtotal thyroidectomy. J. Clin. Invest., 1946, 25, 404.

2. Winkler, A. W., Riggs, D. S., and Man, E. B., Serum iodine in hypothyroidism before and during thyroid therapy. J. Clin. Invest., 1945, 24, 732.

3. Lowenstein, B. E., Bruger, M., and Hinton, J. W., The protein-bound plasma iodine in patients with thyroid disease. I. Correlation with basal heat production. J. Clin. Endocrinol., 1944, 4, 268.

4. Lowenstein, B. E., Bruger, M., Hinton, J. W., and Lough, W. G., The protein-bound plasma iodine in patients with thyroid disease; effect of thiouracil. J. Clin. Endocrinol., 1945, 5, 181.

5. Man, E. B., Smirnow, A. E., Gildea, E. F., and Peters, J. P., Serum iodine fractions in hyperthyroidism. J. Clin. Invest., 1942, 21, 773.

6. Riggs, D. S., Gildea, E. F., Man, E. B., and Peters, J. P., Blood iodine in patients with thyroid disease. J. Clin. Invest., 1941, 20, 345.

7. Salter, W. T., Bassett, A. M., and Sappington, T. S., Protein-bound iodine in blood. II. Its relation to thyroid function in 100 clinical cases. Am. J. M. Sc., 1941, 202, 527.

8. Talbot, N. B., Butler, A. M., Saltzman, A. H., and Rodriguez, P. M., The colorimetric estimation of protein-bound serum iodine. J. Biol. Chem., 1944, 153, 479.

9. Peters, J. P., and Van Slyke, D. D., Quantitative Clinical Chemistry, Vol. I, Interpretations. Williams and Wilkins Co., Baltimore, 1946, Ed. 2.
10. Harding, V. J., Metabolism in pregnancy. Physiol. Reviews, 1925, 5, 279.

11. Root, H. F., and Root, H. K., The basal metabolism during pregnancy and the puerperium. Arch. Int. Med., 1923, 32, 411.

12. Rowe, A. W., and Boyd, W. C., The metabolism in pregnancy. IX. The foetal influence on the basal rate. J. of Nutrition, 1932, 5, 551.

13. Sandiford, I., and Wheeler, T., The basal metabolism before, during and after pregnancy. J. Biol. Chem., 1924, 62, 329.

14. Sandiford, I., Estimation of the surface area of the fetus, and a graphic comparison of the various surface area formulas. J. Biol. Chem., 1924, 62, 323.

15. Riggs, D. S., and Man, E. B., A permanganate acid ashing micromethod for iodine determinations. I. Values in blood of normal subjects. J. Biol. Chem., 1940, 134, 193.

16. Winkler, A. W., Danowski, T. S., and Man, E. B., Unpublished data.

17. Danowski, T. S., Man, E. B., and Winkler, A. W. Additive effects of iodine and thiourea in the treatment of hyperthyroidism. J. Clin. Invest., 1946, 25, 597.

18. Danowski, T. S., Man, E. B., and Winkler, A. W., Treatment of hyperthyroidism with a combination of iodine, thiourea in small doses, and desiccated thyroid. Am. J. M. Sc., 1945, 210, 777.

19. Kurzrok, R., Studies on the problem of repeated miscarriage; genital hypoplasia. I. Genital hypoplasia. New York State J. Med., 1946, 46, 493.

20. David, N. A., and Zener, F. B., Influence of iodine therapy on blood iodine and basal metabolic rate in pregnancy. Fed. Proc., 1947, 6, 320.

21. Curtis, G. M., and Fertman, M. B., Blood iodine studies. VII. The relation of the basal metabolic rate to the blood iodine in thyroid disease. Ann. Surg., 1945, 122, 963.

22. Taurog, A., and Chaikoff, I. L., On the determination of plasma iodine. J. Biol. Chem., 1946, 163, 313.

23. Duncan, G., Diseases of Metabolism; Chapter XVII, p. 896, Diseases of Thyroid Gland, Winkler, A. W. W. B. Saunders Co., Philadelphia, 1947.

24. Riggs, D. S., Man, E. B., and Winkler, A. W., Serum iodine of euthyroid subjects treated with desiccated thyroid. J. Clin. Invest., 1945, 24, 722. 